\title{
Wieslaw Mateusz Malinowski, Le Roman du symbolisme (Bourges, Villiers de l'Isle-Adam, Dujardin, Gourmont, Rodenbach)
}

\section{Seth Whidden}

\section{(2) OpenEdition \\ 1 Journals}

\section{Édition électronique}

URL : https://journals.openedition.org/studifrancesi/39701

DOI : 10.4000/studifrancesi.39701

ISSN : 2427-5856

Éditeur

Rosenberg \& Sellier

\section{Édition imprimée}

Date de publication : 1 décembre 2004

Pagination : 404

ISSN : 0039-2944

\section{Référence électronique}

Seth Whidden, «Wieslaw Mateusz Malinowski, Le Roman du symbolisme (Bourges, Villiers de I'Isle-Adam, Dujardin, Gourmont, Rodenbach) », Studi Francesi [En ligne], 143 (XLVIII | II) | 2004, mis en ligne le 30 novembre 2015, consulté le 19 mai 2021. URL : http://journals.openedition.org/studifrancesi/39701 ; DOI : https://doi.org/10.4000/studifrancesi.39701

Ce document a été généré automatiquement le 19 mai 2021.

\section{cc) $($ ) $\ominus$}

Studi Francesi è distribuita con Licenza Creative Commons Attribuzione - Non commerciale - Non opere derivate 4.0 Internazionale. 


\title{
Wieslaw Mateusz Malinowski, Le Roman du symbolisme (Bourges, Villiers de l'Isle-Adam, Dujardin, Gourmont, Rodenbach)
}

\author{
Seth Whidden
}

\section{RÉFÉRENCE}

WIESLAW MATEUSZ MALINOWSKI, Le Roman du symbolisme (Bourges, Villiers de l'Isle-Adam, Dujardin, Gourmont, Rodenbach), Poznan (Pologne), Presses universitaires Adam Mickiewicz, "Filologia Romanska", no 27, 2003, pp. 231.

1 Évoquer le roman du symbolisme est moins évident qu'on ne le croit: quelles sont les limites entre symbolisme, décadence et naturalisme, entre prose, prose poétique et poésie? À l'aide de cinq romans bien choisis, W.M.Malinowski répond entre autres à ces questions au cours d'une étude, sinon élégante, du moins érudite, bien organisée et intéressante. Comme le montrent Le Crépuscule des Dieux de Bourges; L'Ève future de Villiers de l'Isle-Adam, Les Lauriers sont coupés de Dujardin, Sixtine de Gourmont et Bruges-la-Morte de Rodenbach, la période 1884-1892 s'est avérée propice à l'avènement d'un type de roman caractérisé par son propre traitement de l'individu et une vision particulière du monde autour de lui.

2 Suivant une introduction qui définit en détail le symbolisme dans son contexte, les cinq chapitres de l'ouvrage sont consacrés à l'étude des cinq romans en question. Tissant à la fois sa toile à base de critique littéraire, de concepts philosophiques et de citations du roman, Malinowski présente chaque roman de manière à illustrer son caractère unique et révélateur du symbolisme: la musique de Wagner chez Bourges, l'idéal chez Villiers, le monologue intérieur chez Dujardin, l'influence schopenhauerienne chez Gourmont et une version des correspondances chez Rodenbach. En fin d'ouvrage, une synthèse 
explique comment, par ses thèmes récurrents, le roman du symbolisme se veut différent du naturalisme: le psychique domine l'action, l'idéal et l'irréel l'emportent sur le réel, l'écriture poétique sur la narration réaliste. Ajoutons une forte présence de la musique (tantôt comme leitmotiv, tantôt dans une structure dite «symphonique»), ainsi qu'une hybridation des formes (dépassant les limites romanesques traditionnelles) et l'esthétique de l'inachevé (l'insuffisance de la vie et du récit face à l'Idéal), lesquelles témoignent moins d'une approche fixe comme le naturalisme que d'une forme d'expression provoquant sa propre métamorphose. 